\title{
Ultrasounds and social attraction in rats: Concomitants or determinants?
}

\author{
RICHARD BORDEN, MARCUS R. WALKER, and BIBB LATANÉ \\ Ohio State University, Columbus, Ohio 49210
}

\begin{abstract}
If the ultrasonic vocalizations uttered by rodents during a variety of social activities serve as a primary channel of social communication, then eliminating the ability to detect them should affect social interaction. Pairs of rats deafened by two different techniques (Experiment 1, ossicular displacement and ear plugging; Experiment 2, auditory over-stimulation) were as gregarious when freely interacting in an open field as normal rats, indicating that ultrasonic vocalizations are not the source of social attraction for this species. In addition, the temporal patterning of social contacts between deaf pairs and normal pairs was virtually identical, indicating that ultrasounds may not serve a necessary communicative or regulatory function in social interaction. It seems possible that the function of rats' ultrasonic vocalizations may be more expressive than communicative.
\end{abstract}

For many years, scientists have recognized that bats, porpoises, and some species of insects utilize ultrasonic pulses for detecting and avoiding objects in their paths (Griffin \& Galambos, 1941; Kellogg, Kohler, \& Morris, 1953; Pierce, 1948; Pierce \& Griffin, 1938). However, the fact that rodents also emit ultrasonic vocalizations was not discovered until 1954, when J. W. Anderson (1954) pointed a "bat detector" in the direction of a laboratory rat. Apparently, in addition to the occasional audible sniff or squeal, rats also produce a wide array of noises in the range of 20 to $80 \mathrm{kHz}$ (Sewell, 1967, 1970). While some researchers have sought to demonstrate that these ultrasounds are used as a means of echolocation (Bell, Noble, \& Daves, 1971; Riley \& Rosenzweig, 1957; Rosenzweig, Riley, \& Krech, 1955), others have attempted to determine whether they serve as social signals.

Recent research on the social behavior of adult rats has revealed that identifiable ultrasounds are often associated with a variety of specific behavioral sequences, including maternal retrieval (Allin \& Banks, 1972), mating (Barfield \& Geyer, 1972), and aggressive altercation (Sales, 1972; Luciano, Note 1). This evidence has led a number of investigators to speculate that ultrasounds provide rats with an important channel of communication. Some believe that one important function of these sounds is a "desist contact signal" (Barfield \& Geyer, 1972) which controls approach behavior and allows an animal "to perform essential activities" (Sales, 1972). Others have been more skeptical, noting that "the utility of ultrasound production to rodent species remains essentially conjectural. Evi-

This research was supported by an Ohio State University postdoctoral fellowship to R. B., by an Ohio State University Fellowship to M. R. W., and by NSF Grants GS27340 and GS40194 to B. L. We thank Michael Harris and Glenn Rutter for their assistance. Richard Borden is now at the Department of Psychological Sciences, Purdue University. Request reprints from B. Latané, 404-C West 17 th Avenue, Columbus, Ohio 43210. dence for the effect of ultrasounds on adult rodents is primarily correlational or circumstantial in nature" (Allin \& Banks, 1972).

The present study provides evidence from two experiments conducted to test the effect of removing the possibility of ultrasonic communications on social attraction in rats. If rat vocalizations serve to attract rats to each other, rats with impaired hearing should spend less time together than rats with normal hearing. If, on the other hand, ultrasonic vocalizations serve to regulate contact duration, one would expect the durations of contacts between deafened rats to be longer and more variable than contacts between normal animals.

\section{EXPERIMENT 1}

\section{Method}

Subjects in the first experiment were 48 experimentally naive 90-day-old male albino rats (Sprague-Dawley). Each animal was individually housed and fed and watered ad lib.

Ten days following their arrival, all subjects received intraperitoneal injections of Nembutal $(.1 \mathrm{cc} / 100 \mathrm{~g})$. and Atropine $(.2 \mathrm{cc})$. Twenty-four rats were then surgically deafened by (1) cleansing the external meatus of both ears with an alcohol solution, (2) rupturing the eardrums with a blunt probe, (3) displacing the ossicles, (4) plugging the middle ear canal with a mixture of cotton and collodion, and (5) filling the external ear canal with Super-Rubber, a liquid dental compound which hardens to form snug-fitting permanent rubber plugs. The effectiveness of Steps 1-4 was checked with the aid of a smallcaliber otoscope. ${ }^{1}$ The remaining 24 animals served as control subjects.

The procedure appeared to be uniformly successful. None of the treated subjects showed either the characteristic startle response or pinna reflex to loud sounds immediately following recovery or during subsequent testing. No overt disturbances in equilibrium followed the procedure, and the Super-Rubber plugs remained intact throughout the experiment.

Pairs of deaf and pairs of normal rats were allowed to run about freely in a 4 -ft-diam open field, $5 \mathrm{~min} /$ day for 6 consecutive days (for a more detailed description of the testing situation, see Latané, 1969). During the experimental sessions, one ob- 
server recorded the duration of each contact period, each noncontact period, and also the total time in contact for each pair of animals. Another observer recorded each animal's location in the field at 10 -sec intervals. These location scores were subsequently used to calculate the average interanimal distance for each pair of animals and to measure the distance traveled per $10 \mathrm{sec}$ by the individual animals. ${ }^{2}$ The number of boluses deposited by the animals during a session was recorded as an additional index of emotionality.

\section{Results}

The hypothesis that rats are attracted to one another because of the ultrasounds they produce was tested by a groups by days analysis of variance on the average time in contact per session. Percent time in contact for deaf and normal pairs differed only trivially [ $46.7 \%$ vs $42.5 \%$, respectively $(\mathrm{F}<1, \mathrm{n} . \mathrm{s})$.$] and did not interact with days$ $(\mathrm{F}=1.29$, $\mathrm{df}=5 / 110$, n.s. $)$. As in previous research, however, time in contact did increase significantly across days of testing $(\mathrm{F}=12.10, \mathrm{df}=5 / 110, \mathrm{p}<.001)$ and minutes within sessions $(F=25.01, \mathrm{df}=4 / 88, \mathrm{p}<.001$, indicating that the measure was highly sensitive to known effects. ${ }^{3}$ In addition, deaf and normal animals showed no sign of differences in sociability measured in terms of either number of contacts $(12.3$ vs $14.8, \mathrm{~F}=$ $1.13)$ or the average distance the animals maintained between one another $(12.0$ vs 13.1 in., $F<1)$.

Although ultrasounds clearly are not in themselves the source of social attraction, it is still possible that they serve to regulate contact, allowing rats to "tell" each other when to come together or go apart. If this were so, we would expect differences in the variance of the individual contact durations. In order to test this hypothesis, the variance of the contact durations within each session was computed for each pair of animals. The variance scores were then subjected to a groups by days analysis of variance. The contact behavior of deaf pairs was not more variable than that of normals $(F<1)$.

Finally, comparisons of deaf and normal pairs on measures of activity (movement) and emotionality (boluses) also failed to provide any indication of significant effects (all Fs nonsignificant). Apparently, the ability to hear ultrasounds was of little importance in determining rats' contact, spacing, activity, or emotional behavior.

In order to reaffirm this conclusion, a complete replication of the preceding experiment was conducted. The replication experiment was identical to the previous experiment, with the exception that deafness in this case was induced by auditory over-stimulation.

\section{EXPERIMENT 2}

\section{Method}

The subjects were 40 male albino rats (Sprague-Dawley), 90 days old at the start of testing. Twenty rats were anesthetized and placed individually in an auditory stimulation chamber and subjected to a $90-\mathrm{min}$ presentation of a $2,000-\mathrm{Hz}$ tone at $145 \mathrm{~dB}^{4}$ The 20 control subjects were also anesthetized and placed in the chamber for a comparable period of silence.
Following recovery and on subsequent days of testing, the aurally over-stimulated subjects showed no signs of response to intense sounds from either the audible or ultrasonic ranges.

\section{Results}

The 10 pairs each of normal and deaf animals were then tested for 6 consecutive days in the same fashion as in Experiment 1. Again, percent time in contact of deaf and normal subjects was virtually identical $(38.0 \%$ vs $38.7 \%, F<1)$, as were number of contacts $(14.5$ vs $14.8, \mathrm{~F}<1)$ and average distance $(16.8$ vs 16.7 in., $\mathrm{F}<1)$. Time in contact increased $(\mathrm{F}=5.23, \mathrm{df}=5 / 90, \mathrm{p}<.001)$ and average distance decreased $(F=5.45, p<.001)$ across days of testing, but no significant Groups by Days interactions emerged. The comparison of contact variances also failed to provide either a significant main effect or interaction with days of testing ( Fs $<1)$. Finally, the activity and emotionality measures for deaf and normal subjects were again identical (all Fs nonsignificant). Thus, all measures of sociability and emotionality again failed to provide any support for the notion that the ability to hear has any effect on social interaction in rats. The measures, however, were again extremely sensitive to known day of testing effects.

\section{SUBSIDIARY EXPERIMENT}

In a subsidiary experiment we tested 12 120-day-old male albino rats individually and in pairs in a 2-ft-diam circular open field located in a large $225-\mathrm{ft}^{2}$ soundproof test facility in the Herrick Laboratories of Purdue University. Each rat was tested individually for $5 \mathrm{~min}$ and again, about $1 \mathrm{~h}$ later, for $10 \mathrm{~min}$ with another rat. Rats were allowed to run around freely as in the present experiments, but a Brüel and Kjaer $41331 / 2$-in. free-field condensor microphone connected to a B \& K Type 2603 microphone amplifier, bandpass filter set, and Type 2305 sound-level recorder was suspended 12 in. overhead. Nine of the 12 rats produced some ultrasounds during the $5 \mathrm{~min}$ of individual testing and five of the six pairs produced ultrasounds when tested in pairs. These ultrasounds ranged in frequency from $20 \mathrm{~K}$ to $80 \mathrm{~K}$ and occurred when the animals were moving, still, apart, and together. Thus, although direct measures of the emission of ultrasounds were not taken during Experiments 1 and 2, we do know that rats make such noises in settings similar to those we employed.

\section{DISCUSSION}

In a recent study of ultrasonic vocalization among rodents, Sales (1972) concluded that "ultrasounds probably play an important and hitherto unsuspected role in the social life of many species of myomorph rodents."

The results of the present studies fail to support this contention, at least for rats. The social behavior of deaf subjects was virtually identical to the behavior for normal subjects on all measures of sociability. The fact that the gregariousness of both groups increased within days as well as across days in an identical fashion provides evidence for the sensitivity of the measures and 
suggests that the ability to hear may be of minimal importance to social attraction among members of this species.

One resolution of the present results with previous research on ultrasounds would be to suggest that the communicative role of these sounds is limited to certain instinctive, preprogrammed behavioral sequences (e.g., aggressive, maternal, and sexual behaviors). It is possible that deafened animals in settings which evoke such behaviors would indeed be at a disadvantage. Another possibility, however, is that ultrasounds are simply concomitants rather than determinants of rodent social behavior. Until the appropriate research is done, we think it unwise to assume that the existance of ultrasounds implies that rats use them to talk to each other.

Previous research examining the stimulus qualities of rats has revealed that the appearance, feel, and smell of a rat has little to do with its social attractiveness (Latané \& Hothersall, 1972; Latané, Meltzer, Joy, Lubell, \& Cappell, 1972; Werner \& Latané, 1974). The present data indicate that the ability of rats to hear one another may also be of minimal importance in determining physical attraction. Consequently, these results may be viewed as additional support for the Latane et al. (1972) conclusion that social attraction among rats is mediated by "dynamic qualities, such as movement or social responsiveness," rather than the way that a rat looks, feels, smells, or sounds.

\section{REFERENCE NOTE}

1. Luciano, D. Sensory control of intraspecific aggression in laboratory rats. First International Congress on Aggression, Toronto, 1974.

\section{REFERENCES}

Allin, J. T., \& Banks, E. M. Functional aspects of ultrasound production by infant albino rats (rattus norvegicus). Animal Behavior. 1972, 20, 175-185.

Anderson, J. W. The production of ultrasonic sounds by laboratory rats and other mammals. Science, 1954, 119 , 808-809.

Barfield, R. J., \& Geyer, L. A. Sexual behavior: Ultrasonic post-ejaculatory song of the male rat. Science, 1972, 176, 1349-1350.

Bell, R. A., Noble, M. E., \& Daves, W. F. Echolocation in the blinded rat. Perception \& Psychophysics, 1971, 10, 112-114.

Eckman, J., Meltzer, J. D., \& Latanb́, B. Gregariousness in rats as a function of familiarity of environment. Journal of Personality and Social Psychology, 1969, 11, 107-114.

Gould, E., Negus, N. C., \& Novick, A. Evidence for echolocation in shrews. Journal of Experimental Zoology, 1964, 156, 19-38.

Griffin, D. R., \& Galambos, R. The sensory basis of obstacle avoidance by flying bats. Journal of Experimental Zoology, 1941, 86, 481-506.

Honzik, C. H. The sensory basis of maze learning in rats. Comparative Psychology Monographs, 1936, 13, 1-113.

Kellogg, W. N., Kohler, R., \& Morris, H. N. Porpoise sounds as sonar signals. Science, 1953, 117, 239-243.

LATANÉ, B. Gregariousness and fear in laboratory rats. Journal of Experimental Social Psychology, 1969, 5, 61-69.

LATANÉ, B., \& Hothersall, D. Social attraction in animals. In P. C. Dodwell (Ed.), New horizons in psychology 2. Baltimore, Md: Penguin, 1972. latané, B., Meltzer, J., Joy, V., Lubell, B., \& Cappell, H. Stimulus determinants of social attraction in rats. Journal of Comparative and Physiological Psychology, 1972, 79, 13-21.

LAtané, B., \& Walton, D. Effects of social deprivation and familiarity with the environment on social attraction in rats. Psychonomic Science, 1972, 27, 9-11.

Pierce, G. W. The song of insects. Harvard University Press: Cambridge, 1948.

Pierce, G. W., \& Griffin, D. R. Experimental determination of supersonic notes emitted by bats. Journal of Mammology, 1938, 19, 454-455.

Riley, D. A., \& Rosenzweig, M. R. Echolocation in rats. Journal of Comparative and Physiological Psychology, 1957, 50, 323-328.

Rosenzweig, M. R., Riley, D. A., \& Krech, D. Evidence for echolocation in the rat. Science, 1955, 121, 600 .

SALES, G. D. Ultrasound and aggressive behavior in rats and other small animals. Animal Behavior, 1972, 20, 88-100.

SEwEll, G. D. Ultrasound in adult rodents. Nature, 1967, 215, 512 .

SEWELL, G. D. Ultrasonic signals from rodents. Ultrasonics, 1970, 8, 26-30.

SEWELL, G. D. Ultrasonic communication in rodents. Nature, 1970, 227, 410.

Stockwell, C. W., Ades, H. W., \& Engstrom, M. D. Patterns of hair cell damage after intense auditory stimulation. Annals of Otology, Rhinology, and Laryngology, 1969, 78, 1144-1169.

WERNER, C., \& LATANÉ, B. Interaction motivates attraction: Rats are fond of fondling. Journal of Personality and Social Psychology, 1974, 29, 328-334.

\section{NOTES}

1. Similar procedures have been used in echolocation studies with bats (Pierce \& Griffin, 1938), rats (Honzik, 1936; Rosenzweig, Riley, \& Krech, 1955), and shrews (Gould et al., 1964).

2. Duration of contact and noncontact intervals was recorded on an Esterline-Angus event recorder. Total time in contact was recorded on a Lafayette 54015 digital display stop clock in parallel with the event recorder. The distance and activity measures were calculated with the aid of computer programs RATLOVE, by V. Joy and D. Poor, and RATPLACE, by M. R. Walker.

3. See studies cited in Latané and Walton (1972). They and Eckman, Meltzer, and Latané (1969) suggest that rats become more affiliative over days as the testing environment becomes more familiar and competing fear and exploratory responses drop out.

4. Stockwell, Ades, and Engstrom (1969) have shown that a pure tone of this frequency and sound-pressure level produces deafness by means of extensive permanent damage to the receptor cells in the organ of Corti. We thank Dr. C. W. Stockwell, Dr. D. Lim, and Mr. D. Stutes of the Ohio State Medical School for advice and use of their facilities. The auditory signal was produced by a Hewlitt-Packard 201 oscillator and amplified with a Dukane 300-W amplifier. Eight Alpec 290C drivers delivered the amplified signal into the 3-ft-diam stimulation chamber, which was located on a table top in an IAC acoustical chamber. The SPL of the output signal was continuously monitored with a B \& K condensor microphone; its variation was less than $2 \mathrm{~dB}$ throughout the presentation of the $2,000-\mathrm{Hz}$ tone.

(Received for publication January 12, 1977.) 